\title{
The Model and Elements of a Palliative Care Plan for Patients with Terminal IIIness: A Systematic Review
}

\author{
Nita Arisanti ${ }^{1 *}$, Panji F Hadisoemarto ${ }^{1}$, Elsa Pudji Setiawati Sasongko ${ }^{1}$, Veranita Pandia² ${ }^{2}$ Dany Hilmanto ${ }^{3}$
}

\begin{abstract}
Background: Palliative care has been a part of the healthcare system in Indonesia since its introduction in 1989; however, few formal institutions provide palliative care. Access to care, inconsistency in the standard of care, conflicting healthcare guidelines, inadequate healthcare funding, sociocultural values, disease patterns, and antiquated health systems within the country all help to contribute to this situation. The aim of this study was to conduct a systematic literature review analyzing models of palliative care and elements of a model for palliative care. Methods: The literature was searched in four electronic databases: Medline, PubMed, Web of Science, and the National Institute for Health and Care Excellence (NICE) Database. Three reviewers screened the search results and the data were classified according to the main objective. Further synthesis was conducted to demonstrate elements for a model of care. Results: The initial search strategy identified 207 articles. Based on the Hawker quality assessment scale, only 14 articles met the criteria for review and synthesis. Of these 14 articles, four described palliative care for chronic diseases (such as heart failure and end-stage renal disease) and 10 for cancer. The integrated palliative care model has been the most frequently described. The other models are respite care, care-aide, the personal alarm model, family-centered advanced care, and end-of-life care for young adults. This systematic review also identified elements for a model of palliative care and categorized them as patient and family, personnel, and healthcare system models. Conclusion: There are various studies describing models and their elements for palliative care. The integrated palliative care model has been the most frequently described.
\end{abstract}

\section{Keywords}

end-of-life care; integrated palliative care model; model of care; quality of life

${ }^{1}$ Department of Public Health, Faculty of Medicine, Universitas Padjadjaran

${ }^{2}$ Department of Psychiatric, Faculty of Medicine, Universitas Padjadjaran

${ }^{3}$ Department of Child Health, Faculty of Medicine, Universitas Padjadjaran

\section{Corresponding author}

Nita Arisanti: Department of Public Health, Faculty of Medicine, Universitas Padjadjaran

Email: nita.arisanti@unpad.ac.id

\begin{tabular}{ll} 
& \multicolumn{1}{c}{ Contents } \\
& Introduction \\
$\mathbf{1}$ & Methods \\
1.1 & Selection Criteria \\
1.2 & Inclusion Criteria \\
1.3 & Exclusion Criteria \\
1.4 & Search Strategy \\
1.5 & Study Selection \\
1.6 & Data Extraction \\
1.7 & Data Synthesis \\
1.8 & Ethical Approval \\
$\mathbf{2}$ & Results \\
2.1 & Study Selection \\
2.2 & Study Characteristics and Methodological Quality \\
2.3 & Models of Palliative Care \\
2.4 & Elements of Palliative Care \\
2.5 & Outcomes of Care \\
$\mathbf{3}$ & Discussion \\
3.1 & Principal Findings of the Review \\
3.2 & Strengths and Limitations \\
$\mathbf{4}$ & Conclusion \\
4.1 & Authors' Contribution \\
$\mathbf{5}$ & Acknowledgments \\
5.1 & Competing Interests \\
5.2 & Availability of Data and Materials \\
5.3 & Consent for Publication \\
5.4 & Ethics Approval and Consent to Participate \\
$\mathbf{6}$ & References \\
&
\end{tabular}

\section{Introduction}

There is an increasing number of both adult and children with chronic illness who are terminally ill or at the end stages of life; and will require comprehensive healthcare, such as palliative care. Palliative care is a comprehensive form of healthcare aimed to improve the quality of life (QOL) for patients with active and progressive disease. [1] This service is provided either in the hospital by palliative specialists or in primary healthcare facilities by doctors, nurses, psychologists, social workers, spiritual service providers, pharmacists, and the community.[1-4] The management of the terminally ill patient is aimed at fulfilling the treatment plan for not only physical symptoms, but also psychological, social and spiritual needs.[5]

The World Health Organization (WHO) recommends that palliative care should be integrated with healthcare in every country. Integrating palliative care into healthcare is often based on models of care.[6] A model of care refers to the way healthcare services are delivered, and offers values and principles for health professionals. Many models of palliative care have already been introduced and implemented; however, a model of care cannot be directly applied in some countries because of the differences in sociocultural norms, disease patterns, and healthcare systems within those countries.[7] 
Palliative care has been a part of the healthcare system in Indonesia since its introduction in 1989.[8] However, few formal institutions provide palliative care. Several factors act as barriers for the implementation of palliative care on a larger scale, including cultural values, socioeconomic factors, patient and family perceptions, attitudes of service providers, a lack of trained personnel, distribution of palliative service facilities, a lack of coordination, and limited funds.[9] One systematic review about the current status of palliative care in Indonesia identified some such barriers, which include a lack of knowledge among healthcare professionals, geographical access to care, and limited access to opioid pain medications.[10] In 2007, the National Policy on Palliative Care was launched by Indonesia's Ministry of Health; however, the policy has not been fully implemented. The consistency of the standard of care, guidelines and funding contribute to this situation.[11] These barriers should be taken into account for developing a model of palliative care in Indonesia.

The current study aimed to conduct a systematic literature review to analyze a model of palliative care and elements for a model of palliative care. This review was performed as a part of the study to develop such a model of in the authors' setting.

This is a systematic literature review and it is reported according to the Preferred Reporting Items for Systematic Reviews and Meta-Analysis (PRISMA) checklist.[12]

\section{Methods}

\subsection{Selection Criteria}

Eligible studies included in this review focused on a model for palliative care. The studies selected were not only limited to randomized controlled trials, but also included observational and qualitative studies.

\subsection{Inclusion Criteria}

The inclusion criteria for the studies included (1) studies that focused on the model for palliative care, with both cancer and non-cancer illness (such as renal failure, thalassemia, and neurological diseases); (2) studies that focused on QOL, outcome of care, and pain relief; (3) studies that assessed the effectiveness of the models empirically (such as experimental, observational, and qualitative studies); (4) studies that scored at least $60 \%$ (above 22/36) on the Hawker quality assessment scale; (5) articles that were published between January 1, 2007 and December 31, 2016; and (6) articles that were written in English.

\subsection{Exclusion Criteria}

Studies that focused on specific palliative care, such as pain management, symptom management, or caregiver management were excluded. Letters, editorials, and conference abstracts were not used.

\subsection{Search Strategy}

A comprehensive search of four electronic databases (Medline, PubMed, Web of Science, and the NICE
Database) was performed to identify articles published between January 1, 2007 and December 31, 2016. Keywords, MESH terms, and search terms were used as a search strategy. The keywords were "(model of care OR care pathway $O R$ patient care management $O R$ patient care plan OR delivery of health care) AND (hospice OR end of life care $O R$ palliative care $O R$ terminal care) $A N D$ (end stage disease OR cancer OR terminally ill OR limiting disease OR dying) AND (quality of life OR outcome of care $O R$ pain relief) NOT (pain management OR symptoms management OR caregiver management)."

\subsection{Study Selection}

Three researchers screened the search results, imported them to Microsoft Excel, and screened the file to remove duplicates. The abstracts were assessed and eligible studies were further screened for full-text review.

\subsection{Data Extraction}

Data were extracted from the included studies and categorized by year of publication, author, study location/ country, sample population, process of usage of outcome measure, study design, study aim, and results.

In this study, the model of care was defined as standardized designs or frameworks to organize care not only for patients with terminal illness, but also for their families and/or their caregivers.[6] The "element of care" was defined as the attribute that configured palliative care service delivery. [13] Three researchers conducted data extraction and reviewed the results to resolve the disagreements. Some articles were excluded during the data extraction if they did not match the study objective, and the remaining articles were extracted independently by two of the researchers.

\subsection{Data Synthesis}

The Hawker quality assessment scale was used to analyze the articles. This tool assessed nine aspects of the study including: abstract/title, introduction/aims, method/data, sampling, data analysis, ethics/bias, results, transferability/ generalizability, and implications/usefulness. Each of these aspects was graded from 1 (very poor) to 4 (very good), generating a maximum total score of 36 . Only studies that scored at least 60\% (above 22/36) were included.[14] Further synthesis was conducted to show models, elements, and outcomes of care. The articles containing both the model and elements of palliative care were also included in the data analysis.

\subsection{Ethical Approval}

The study was conducted with approval from the Medical Research Ethics Commission Faculty of Medicine, Universitas Padjadjaran.

\section{Results}

\subsection{Study selection}

The initial search strategy identified 207 articles (192 from Medline, 10 from Web of Science, and 5 from the NICE database). After initial screening by title and abstract, 17 
articles were eligible for full-text review. Based on the Hawker quality assessment scale, only 14 articles met the criteria for narrative review and synthesis (Figure 1). Of these, four described palliative care for chronic disease (such as heart failure and end-stage renal disease) and 10 for cancer. Six studies were conducted in the United States and the others were conducted in Canada, United Kingdom, The Netherlands, Brazil, Sweden, and Australia.
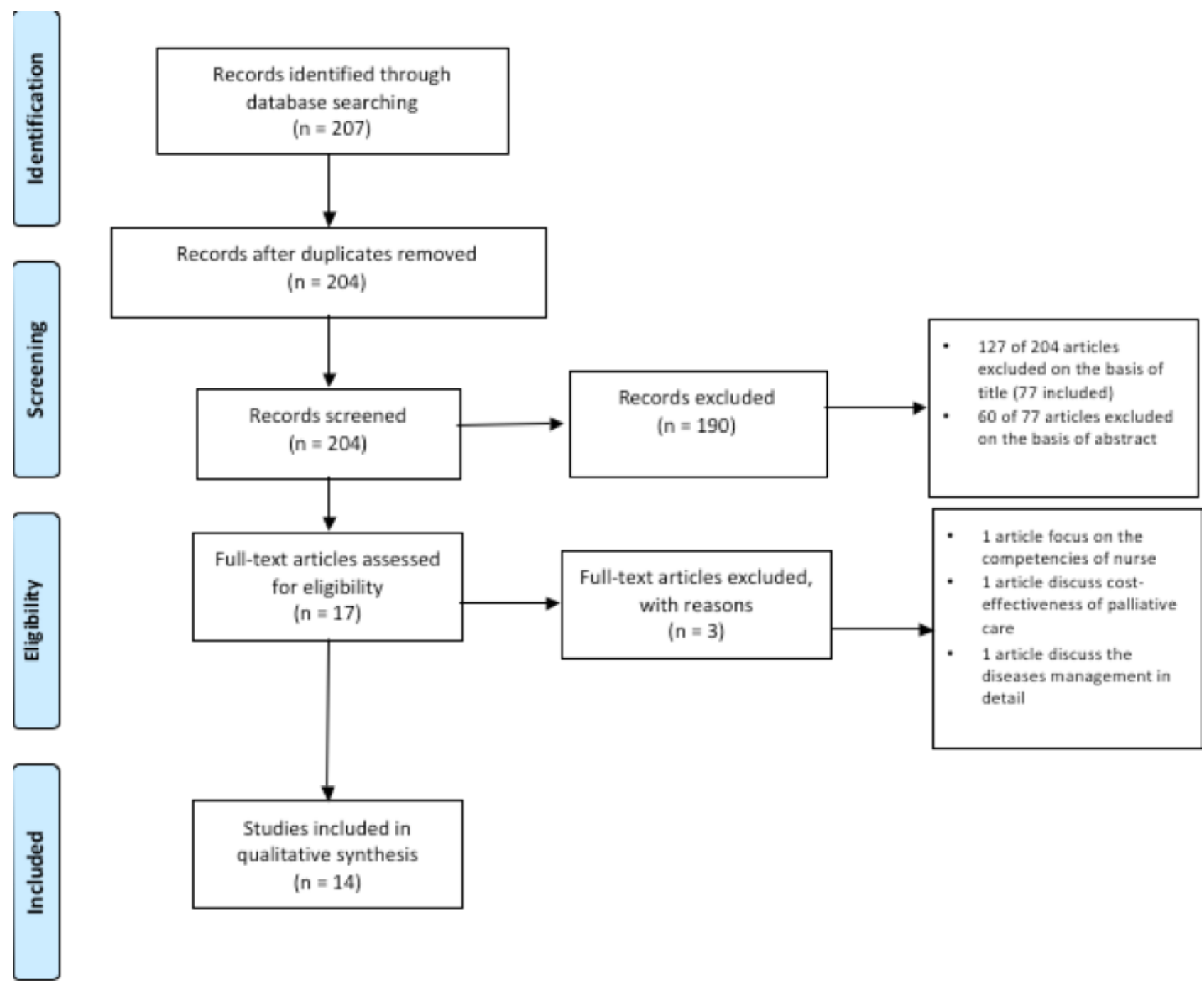

Figure 1 Methodology of screening articles for eligibility in the review (according to PRISMA flow diagram[12])

\subsection{Study Characteristics and methodological quality}

Each of the included studies was assessed for quality of methodology. There were two randomized controlled trials, one quasi-experimental, one prospective cohort, one retrospective cohort, four cross-sectional, one mixed method, and four qualitative studies (Table 1).

The results of the data synthesis were described as a model of palliative care, elements of the model, and outcomes of palliative care.

\subsection{Models of palliative care}

Based on the authors' review, there are various models of palliative care (Table 2).

The models found in this study are described as follows.

1. Carey et al (2016) found that the community respite service has improved the conditions of daily living for patients and their caregivers condition in daily living.
Respite care is temporary care for the relief of caregivers and vulnerable populations, including dying people. It can be a form of daycare, home-respite care or nightcare. Respite care provides benefits such as providing support for patients and their family members, inducing feelings of physiological well-being, self-worth, and self-esteem and reducing social isolation for dying people.[15]

2. Kamal et al (2013) conducted a study in communitybased palliative care to assess QOL. Community-based palliative care is a type of healthcare for patients from a heterogenous population with varying illness, disease severity, and healthcare needs.[16]

3. Levine et al (2016) demonstrated the benefit of integrated care between oncology service and consultative palliative care. This is associated with improvement of the patient experience, QOL, symptom control, survival, and caregiver satisfaction.[17]

4. Rugno et al (2014) also highlighted that early 
Table 2 - Various model of palliative care found in the literature

\begin{tabular}{|c|c|c|c|}
\hline $\begin{array}{l}\text { First author, } \\
\text { year, country }\end{array}$ & Design/method & Disease & Model of palliative care \\
\hline $\begin{array}{l}\text { Carey TA, et } \\
\text { al. } 2016 . \\
\text { Australia. }\end{array}$ & $\begin{array}{l}\text { A cross-sectional } \\
\text { qualitative } \\
\text { study. }\end{array}$ & Chronic disease. & Respite care in the community. \\
\hline $\begin{array}{l}\text { Kamal, AH, et } \\
\text { al. 2013. USA. }\end{array}$ & Prospective cohort. & Cancer. & Community-based palliative care. \\
\hline $\begin{array}{l}\text { Levine, DR, et } \\
\text { al. 2016. USA. }\end{array}$ & Retrospective. & Cancer. & Integrated palliative care. \\
\hline $\begin{array}{l}\text { Rugno FC, et } \\
\text { al.2014. } \\
\text { Brazil. }\end{array}$ & Prospective study. & $\begin{array}{l}\text { Breast or } \\
\text { gynecologic } \\
\text { cancer. }\end{array}$ & Early integrated palliative care. \\
\hline $\begin{array}{l}\text { Brännström } \\
\text { M, et al. } 2013 . \\
\text { Sweden. }\end{array}$ & $\begin{array}{l}\text { Prospective, } \\
\text { randomized study } \\
\text { with an open- } \\
\text { evaluation } \\
\text { PROBE design. }\end{array}$ & Chronic heart failure. & $\begin{array}{l}\text { Integrated heart failure and } \\
\text { palliative advanced home care. }\end{array}$ \\
\hline $\begin{array}{l}\text { Seow H, et } \\
\text { al.2010. } \\
\text { Canada. }\end{array}$ & $\begin{array}{l}\text { Retrospective } \\
\text { observational } \\
\text { cohort study. }\end{array}$ & - & Home-based palliative care \\
\hline $\begin{array}{l}\text { Aoun S, et al. } \\
2012 \\
\text { Australia. }\end{array}$ & $\begin{array}{l}\text { In-depth qualitative } \\
\text { study. }\end{array}$ & $\begin{array}{l}\text { Cancer and non } \\
\text { cancer. }\end{array}$ & $\begin{array}{l}\text { 1. Care-aide model of care. } \\
\text { 2. Personal alarm model of care. }\end{array}$ \\
\hline $\begin{array}{l}\text { Mack, JW, et } \\
\text { al. 2015. USA. }\end{array}$ & $\begin{array}{l}\text { Cross-sectional } \\
\text { study. }\end{array}$ & Cancer. & End of life care for young adult. \\
\hline $\begin{array}{l}\text { Lyon ME, et } \\
\text { al. 2013. USA. }\end{array}$ & $\begin{array}{l}\text { Two-group } \\
\text { randomized } \\
\text { controlled trial in a } \\
\text { pediatric oncology } \\
\text { program. }\end{array}$ & Cancer. & Family-centered advanced care. \\
\hline
\end{tabular}

integration of clinical oncology and palliative care teams could improve QOL, cause patients fewer depression symptoms, and allow patients to receive less chemotherapy in the last 6 weeks of life among advanced breast and gynecological cancers.[18]

5. Seouw et al (2010) conducted a retrospective cohort study to investigate early homecare admission with the demand for hospital resources at the end of life. The authors found that home-based palliative care helps alleviate the use of acute-care services.[19]

6. Brännström et al (2013) identified the effects of integrated palliative advanced homecare and heart failure care. This model provides comprehensive care for severe heart failure patients by early identification of physical, psychological, and social needs of the patient. [20]

7. Aoun et al (2012) explored the expectation of terminally ill "home alone" people. There are two models of care described in this study, (1) the care-aide model of care; and (2) the personal alarm model of care. The care-aide model of care appeared to have provided psychosocial support. This model consists of providing patients with an extra 30 hours of care-aide support. The personal alarm model of care provided increased physical support and an enhanced feeling of independence and security. This model consists of support in emergency situations where the nurse will respond immediately by phone to assess the patient's needs.[21]

8. Mack et al (2015) evaluated end-of-life care among adolescent and young adult patients with cancer. There are different values for end-of-life care for adolescent patients compared with adult patients. The study found that more than two thirds of young patients with cancer received at least one form of intensive end-oflife care.[22] Another study evaluated end-of-life care for young adult patients with cancer and found that the establishment of peer-to-peer support had a positive influence on self-management measured as healthrelated QOL.[23]

9. Lyon et al (2013) found that family-centered, advanced care planning has the potential effect to improve communication between physicians and family regarding treatment goals and care at end of life and to lessen suffering.[24] 


\subsection{Elements of a Model for Palliative Care}

Out of 14 studies, the authors summarized five articles that describe elements of a model for palliative care.

1. Le et al (2014) interviewed 28 clinicians, and four themes related to palliative care emerged. Those themes are: (1) competencies or skills of palliative care providers; (2) care coordination that ensures integrated care, with defined lines of responsibility and clear team communication; (3) an effective and easy referral process, meaning that palliative care has the resources to be responsive to patient and family needs in a timely manner; and (4) delivering patient and family perceptions or concerns about end-of-life care in culturally appropriate ways.[25]

2. Borneman et al (2008) found that an interdisciplinary palliative care team was able to reduce patient-related barriers to symptom management and support QOL. Several themes related to QOL include disease- and treatment-related management, psychological/social/ spiritual concerns, supportive care referral, and interdisciplinary care.[26]

3. Back et al (2014) identified and described distinctive aspects of palliative care from the perception of clinicians. The identified aspects were: (1) symptom management to improve functional status; (2) patient engagement to support coping, accepting, and planning the treatment; and (3) effective communication between the oncologist or specialist and the patient.[27]

4. Bailey C et al (2011) explored end-of-life care in the emergency setting. End-of-life care would be provided based on trajectory of the disease.[28]

\subsection{Outcomes of Care}

In terms of outcomes of care, two studies identified benefits and barriers as outcomes, $[15,26]$ and one study measured the duration of hospitalization or number of emergency room visits before death.[20] The most frequently reported outcomes of care were pain and depression management, QOL, decision making, and the referral process.

\section{DISCUSSION}

\subsection{Principal Findings of the Review}

This study reviewed existing literature in evidence-based models of palliative care for patients with terminal illness, taking into account both cancer and non-cancer diseases. The focus of the study was to identify the model of care and the elements that configure the models of palliative care. The database search resulted in 14 studies that met the inclusion criteria.

Several models of palliative care have been implemented. The integrated palliative care model has been the most frequently described. An integrated healthcare model provides some benefit, such as providing a coordinated and planned healthcare service for individuals by multidisciplinary and interdisciplinary teams. An integrated service model would be implemented if it is supported by effective coordination and cooperation between professionals and better health information systems.[29]

The studies conducted by Brännström et al, Le et al, Rugno et al, and Levine et al described the need for early, integrated palliative care.[17,18,20,25] Such care will lead to better QOL and improve survival for patients.[27]

Healthcare providers should consider the differences between palliative care for young adults, adolescents, and elder patients. One study identified high rates of intensive end-of-life care, especially hospitalizations, among adolescent and young adult patients with cancer.[22] The variation of care between children and adults depends on the disease and symptom spectrum, course and duration of palliative care, administered medication, survival time, and family dynamics.[30,31] A patient's age should be an important aspect to address their special needs when developing a model for palliative care.

This systematic review also identified elements of a model for palliative care and categorized an element from patients, families, healthcare personnel, and healthcare systems. Patients and families should be informed about the care model, and should participate from the beginning of that care. Spiritual beliefs and cultural values of the patient and his or her family also should be considered in providing information about any palliative care received.[25,32]

The competency of healthcare personnel is one of the elements of the model for palliative care. The required competencies in palliative care include clinical skills to manage terminally ill patients, communication skills, and cultural competence.[25] A previous study stated that an integrated palliative care model should be supported by three major elements: (1) good doctor-patient communication; (2) an effective decision-making process; and (3) integration between specialists and general practitioners. Integration of care should be initiated from the beginning of the disease.[33] The success of palliative services needs attention from providers for all aspects of a patient's life; not only the physical pain but also emotional, spiritual, and psychological aspects, so that the involvement of healthcare workers and non-healthcare workers is absolutely necessary. Thus, palliative service is a service that is multidisciplinary and interprofessional; a lack of collaboration between healthcare and non-healthcare workers is a palliative service barrier to patients.[3]

In terms of the healthcare system, effective palliative care models can be organized with the support of consultation models, case management, coordinated care, effective and easy referral processes, service integration, and joint care. $[13,34-36]$

\subsection{Strengths and Limitations}

The strengths of this systematic review are that it focused on palliative care for patients with both cancer and noncancer illnesses in all ranges of age, and used an established 
study appraisal checklist method for analysis.

The limitation of this study is that this review searched for articles focusing on model of care; however, many studies lacked detailed information about model of care. Most of the studies were performed in developed countries, which may impact the generalizability of the findings.

There are several studies describing a model of palliative care and elements for a model for palliative care. The integrated palliative care model has been the most frequently described. More detailed methodological and population specifications are needed to accurately find the results.

\section{Conclusion}

\subsection{Authors' contributions}

NA, EPS and PFH conducted data selection, data extraction and data synthesize. NA drafted the article. All authors analyzed the findings, reviewed the drafts and approved the final manuscript.

The authors would like to thank to Indonesia Endowment Fund for Education (Lembaga Pengelola Dana Pendidikan RI) for supporting this study. The authors acknowledge valuable assistance from Sari Puspa Dewi in searching the articles.

\section{Acknowledgment}

\subsection{Competing interests}

The authors declare that they have no competing interest.

\subsection{Availability of data and materials}

The datasets used and/or analysed during the current study are available from the corresponding author on reasonable request.

\subsection{Consent for publication}

Not applicable.

\subsection{Ethics approval and consent to participate}

The Medical Research Ethics Commission Faculty of Medicine, Universitas Padjadjaran approved the study with registration number 1198/UN6.C10/PN/2017.

\section{References}

1. Tuggey EM, Lewin WH. A multidisciplinary approach in providing transitional care for patients with advanced cancer. Ann Palliat Med. 2014;3(3):139-43.

2. Kaye EC, Rubenstein J, Levine D, Baker JN, Dabbs D, Friebert SE. Pediatric palliative care in the community. CA Cancer J Clin. 2015;65(4):315-33.

3. Oishi A, Murtagh FE. The challenges of uncertainty and interprofessional collaboration in palliative care for non-cancer patients in the community: A systematic review of views from patients, carers and health-care professionals. Palliat Med. 2014;28(9):108198.

4. Jagt-van Kampen CT, Kars MC, Colenbrander DA, Bosman DK, Grootenhuis MA, Caron HN, et al. A prospective study on the characteristics and subjects of pediatric palliative care case management provided by a hospital based palliative care team. BMC Palliat Care. 2017;16(1):1-10.

5. Brinkman-Stoppelenburg A, Boddaert M, Douma J, van der Heide A. Palliative care in Dutch hospitals: a rapid increase in the number of expert teams, a limited number of referrals. BMC Health Serv Res. 2016;16(518):1-7.

6. Siouta N, Van Beek K, van der Eerden ME, Preston N, Hasselaar JG, Hughes S, et al. Integrated palliative care in Europe: a qualitative systematic literature review of empirically-tested models in cancer and chronic disease. BMC Palliat Care. 2016;15(56):1-16.

7. Mitchell GK. Palliative care in Australia. Ochsner J. 2011;11(4):334 7.

8. Kementerian Repubik Indonesia. Keputusan Menteri Kesehatan No. 812 Tahun 2007 tentang Kebijakan Perawatan Paliatif. 2007.

9. Kristanti MS, Setiyarini S, Effendy C. Enhancing the quality of life for palliative care cancer patients in Indonesia through family caregivers: a pilot study of basic skills training. BMC Palliat Care. 2017;16(4):1-7.

10. Rochmawati E, Wiechula R, Cameron K. Current status of palliative care services in Indonesia: a literature review. Int Nurs Rev. 2016;63(2):180-90.

11. Putranto R, Mudjaddid E, Shatri H, Adli M, Martina D. Development and challenges of palliative care in Indonesia: Role of psychosomatic medicine. Biopsychosoc Med. 2017;11(1):1-5.

12. Moher D, Liberati A, Tetzlaff J, Altman DG, Group TP. Preferred Reporting Items for Systematic Reviews and Meta-Analyses : The PRISMA Statement. PLoS Med. 2009;6(7):1-6.

13. Luckett T, Phillips J, Agar M, Virdun C, Green A, Davidson PM. Elements of effective palliative care models: a rapid review. BMC Health Serv Res. 2014;14(136):1-22.

14. Hawker S, Payne S, Kerr C, Hardey M, Powell J. Appraising the evidence: reviewing disparate data systematically. Qual Heal Res. 2002;12(9):1284-99.

15. Carey TA, Schouten K, Wakerman J, Humphreys JS, Miegel F, Murphy S, et al. Improving the quality of life of palliative and chronic disease patients and carers in remote Australia with the establishment of a day respite facility. BMC Palliat Care. 2016;15(62):1-10.

16. Kamal AH, Bull J, Stinson CS, Blue DL, Abernethy AP. Conformance with supportive care quality measures is associated with better quality of life in patients with cancer receiving palliative care. J Oncol Pract. 2013;9(3):e73-6.

17. Levine DR, Johnson L-M, Snyder A, Wiser RK, Gibson D, Kane JR, et al. Integrating palliative care in pediatric oncology: an evolving paradigm for comprehensive cancer care. J Natl Compr Canc. 2016;14(6):741-8.

18. Rugno FC, Paiva BSR, Paiva CE. Early integration of palliative care facilitates the discontinuation of anticancer treatment in women with advanced breast or gynecologic cancers. Gynecol Oncol. 2014;135(2):249-54.

19. Seow H, Barbera L, Howell D, Dy SM. Using more end-of-life homecare services is associated with using fewer acute care services. Med Care. 2010;48(2):118-24.

20. Brännström M, Boman K. A new model for integrated heart failure and palliative advanced homecare - rationale and design of a prospective randomized study. Eur J Cardiovasc Nurs. 2013;12(3):269-75.

21. Aoun S, O'Connor M, Skett K, Deas K, Smith J. Do models of care designed for terminally ill "home alone" people improve their endof-life experience? A patient perspective. Heal Soc Care Community. 2012;20(6):599-606.

22. Mack JW, Chen LH, Cannavale K, Sattayapiwat O, Cooper RM, Chao CR. End-of-life care intensity among adolescent and young adult cancer patients in Kaiser Permanente Southern California. JAMA Oncol. 2015;1(5):592-600.

23. Sattoe JN, Jedeloo S, van Staa A. Effective peer-to-peer support for young people with end-stage renal disease: a mixed methods evaluation of Camp COOL. BMC Nephrol. 2013;14(279):1-14.

24. Lyon ME, Jacobs S, Briggs L, Cheng YI, Wang J. Family-centered advance care planning for teens with cancer. JAMA Pediatr. 2013;167(5):460-7.

25. Le BHC, Mileshkin L, Doan K, Saward D, Spruyt O, Yoong J, et al. 
Acceptability of early integration of palliative care in patients with incurable lung cancer. J Palliat Med. 2014;17(5):553-8.

26. Borneman T, Koczywas M, Cristea M, Reckamp K, Sun V, Ferrell B. An interdisciplinary care approach for integration of palliative care in lung cancer. Clin Lung Cancer. 2008;9(6):352-60.

27. Back AL, Park ER, Greer JA, Jackson VA, Jacobsen JC, Gallagher ER, et al. Clinician roles in early integrated palliative care for patients with advanced cancer: a qualitative study. J Palliat Med. 2014;17(11):1244-8.

28. Bailey C, Murphy R, Porock D. Trajectories of end-of-life care in the emergency department. Ann Emerg Med. 2011;57(4):362-9.

29. Minkman MMN, Ahaus KTB, Huijsman R. A four phase development model for integrated care services in the Netherlands. BMC Health Serv Res. 2009;9(42):1-11.

30. Groh G, Feddersen B, Führer M, Borasio GD. Specialized home palliative care for adults and children: differences and similarities. $\mathrm{J}$ Palliat Med. 2014;17(7):803-10.

31. Walter JK, DeCamp LR, Warrier KS, Murphy TP, Keefer PM. Care of the complex chronically ill child by generalist pediatricians: Lessons learned from pediatric palliative care. Hosp Pediatr. 2013;3(2):12938 .

32. Richardson P. Spirituality, religion and palliative care. Ann Palliat Med. 2014;3(3):150-9.

33. Bone AE, Morgan M, Maddocks M, Sleeman KE, Wright J, Taherzadeh S, et al. Developing a model of short-term integrated palliative and supportive care for frail older people in community settings: perspectives of older people, carers and other key stakeholders. Age Ageing. 2016;45(6):863-73.

34. Baker JN, Hinds PS, Spunt SL, Barfield C, Allen C, Powell BC, et al. Integration of Palliative care principles into the ongoing care of children with cancer: Individualized care planning and coordination. Pediatr Clin North Am. 2008;55(1):142-56.

35. Weaver M, Heinze K, Bell C, Wiener L, Garee AM, Kelly KP, et al. Establishing psychosocial palliative care standards for children and adolescents with cancer and their families: An integrative review. Palliat Med. 2016;30(3):212-23.

36. Kim S-N, Choi S-O, Shin SH, Ryu J-S, Baik J-W. Development of a community-based palliative care model for advance cancer patients in public health centers in Busan, Korea. Cancer Res Treat. 2016;49(3):559-68. 


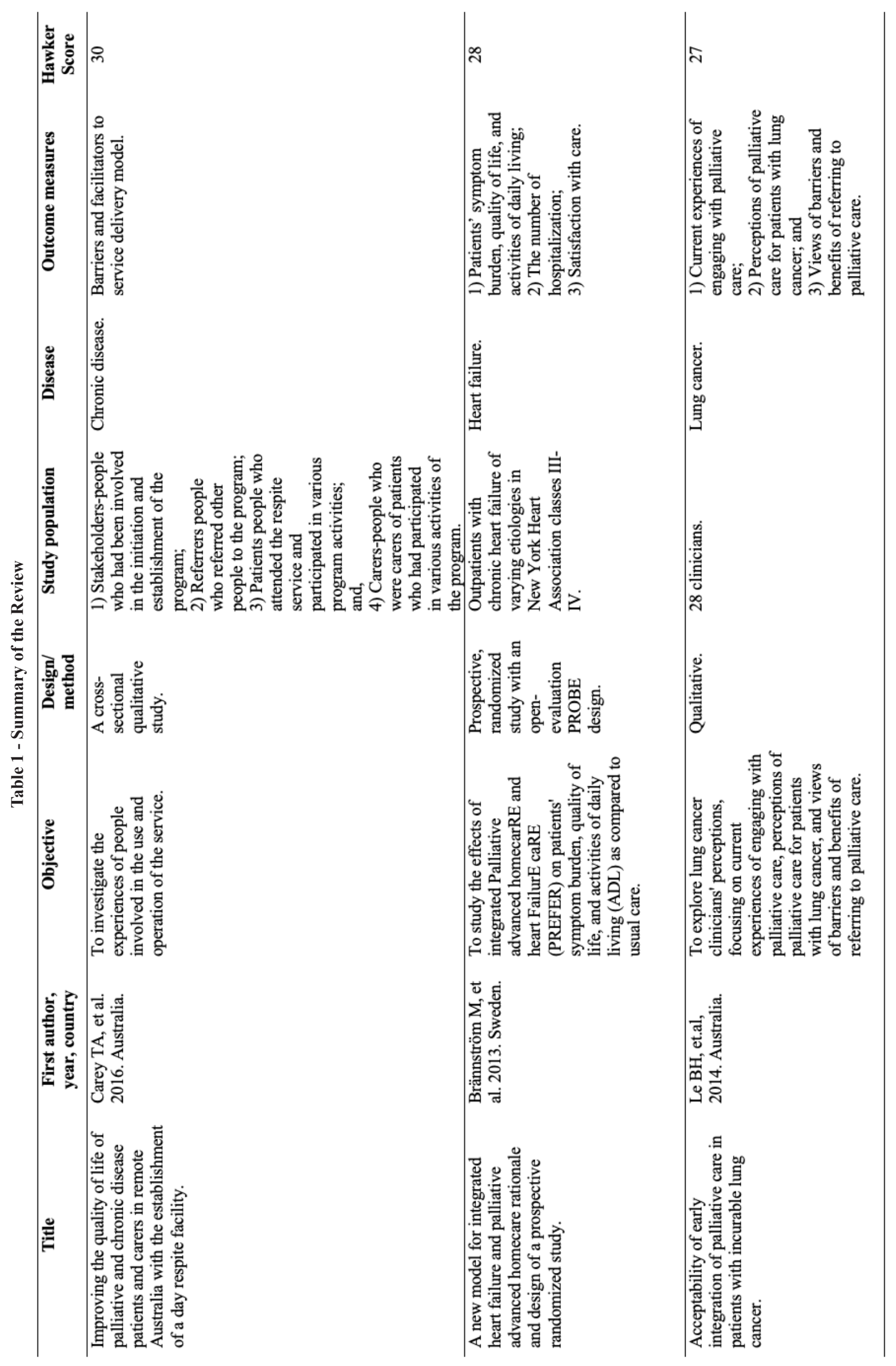



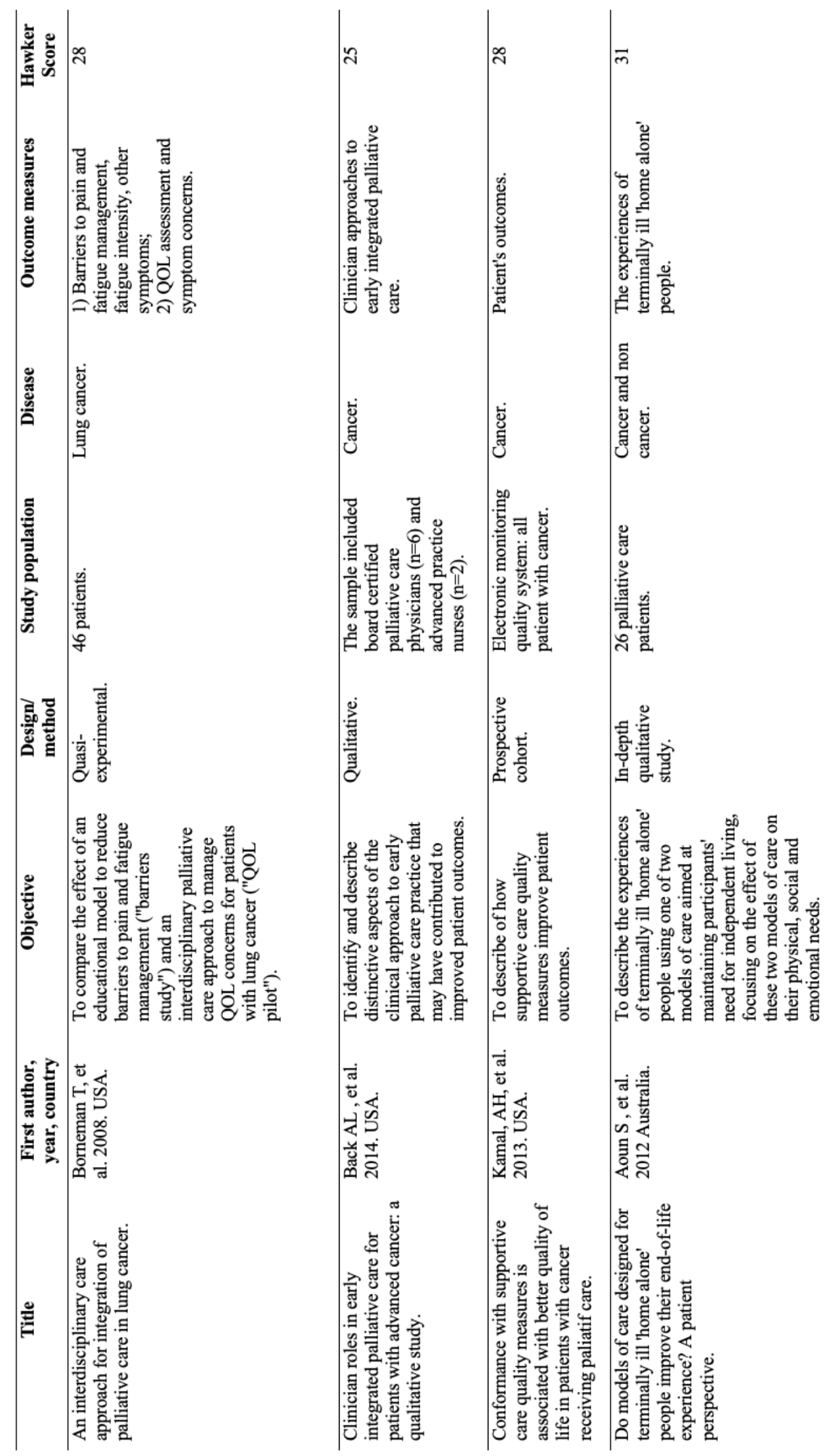

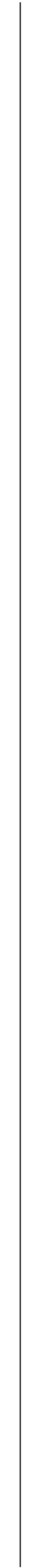



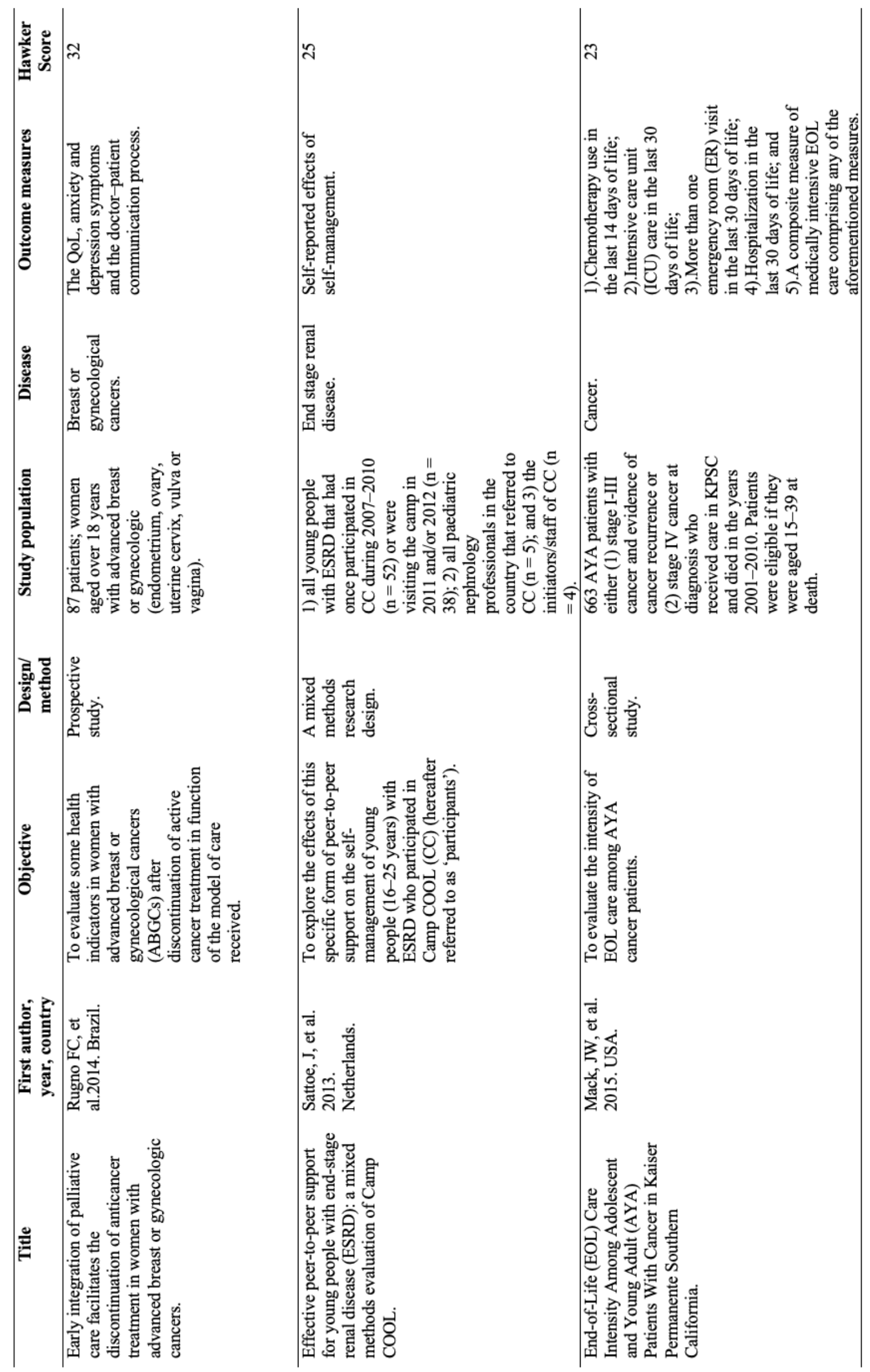


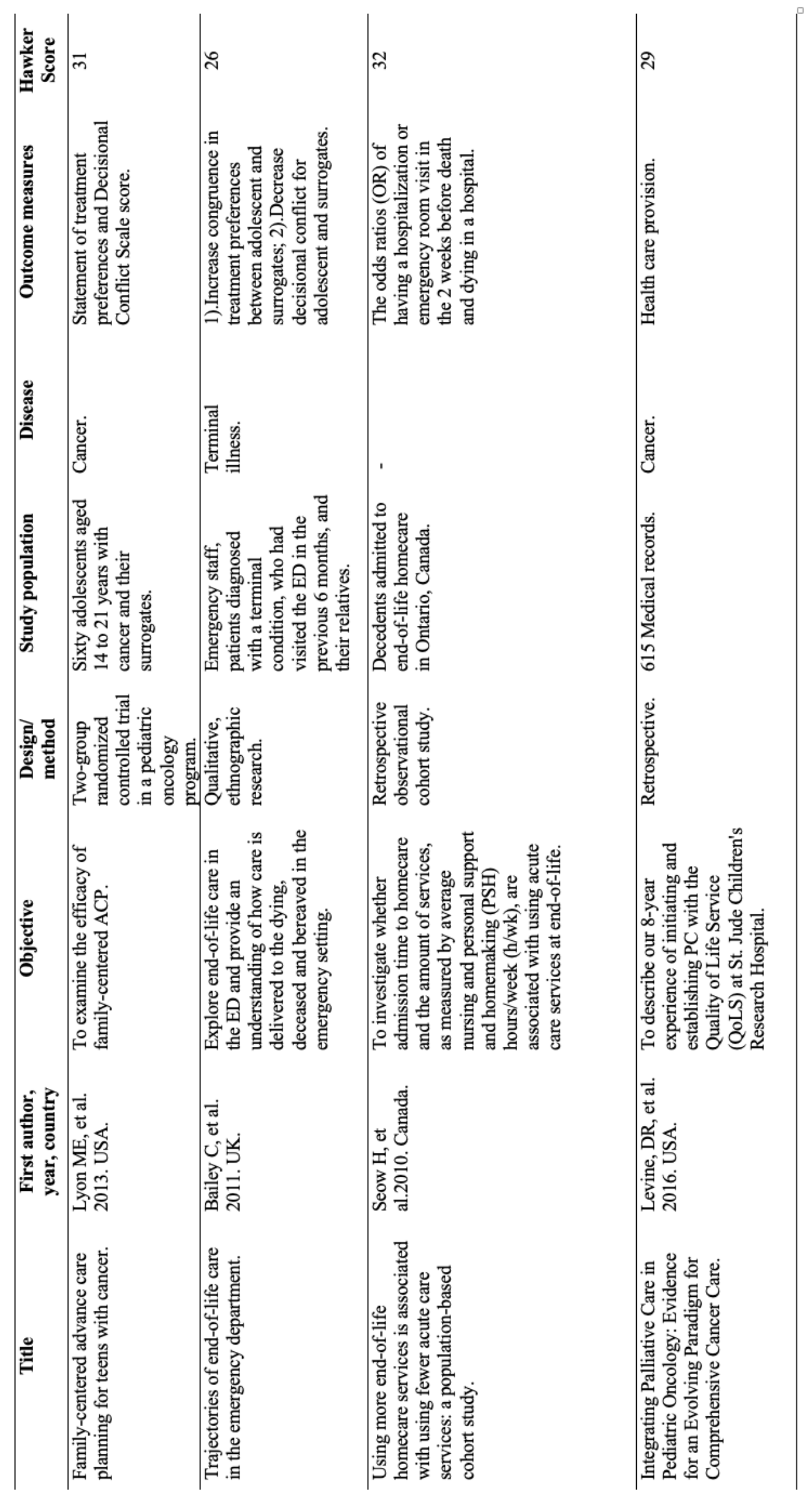

